\title{
Social Media and Academic Performance of Students in Nigerian Tertiary Institutions: The Case of University of Nigeria, Nsukka
}

\section{Rebecca Nwosu ${ }^{1}$, Henry Ajibo ${ }^{2}$, Aloysius Igwe ${ }^{3}$, Aloysius Odii ${ }^{1}$, Theophilus Ndubuisi ${ }^{1}$, Helen Nnadi ${ }^{1}$ and Ijeoma Igwe ${ }^{1}$}

\author{
${ }^{1}$ Department of Sociology \& Anthropology, \\ University of Nigeria, Nsukka, Nigeria \\ ${ }^{2}$ Department of Social Work, \\ University of Nigeria, Nsukka, Nigeria \\ ${ }^{3}$ Institute of African Studies \\ University of Nigeria, Nsukka, Nigeria
}

\begin{abstract}
University age students widely engaged in using Social Media. Therefore, the social media is poised to affecting both their personal and academic lives. Thus, this study is designed to assess the relationship between the use of social media and academic performances, and it impact on the students of sociology/anthropology in university of Nigeria Nsukka. As quantitative approach was adapted to collect the relevant data of study, a number of 120 survey questionnaires were administered among the undergraduates in the Department of Sociology/Anthropology University of Nigeria Nsukka. Out of the three research hypotheses formulated to guide this study, the analysis invalidates the first two hypotheses while validating the last hypothesis. Thus, the students' academic performance is independent of their use of social media $(p=0.808)$; the students' academic performance is also independent of the amount of time they spent on the internet (social media) $(p=0.227)$ and the degree of use of social media by the students is positively related with their ages $(p=0.000)$. The study therefore recommends that the university authority should educate the students on the need to use social media to enhance their academic performance.
\end{abstract}

Keywords: Social media, Academic performance, Students, University.

\section{Introduction}

The advent of the internet in the 1990s led to major developments in the world of communication. This led to the introduction of social networking sites (SNSs). The coming into being of these social media sites revolutionized the world of communication and today we celebrate its improvements ranging from education to entertainment (Kolan and Dzandza, 2018). The latest example of new communication technology usually used by students is social media, also known as Social Networking Sites. The emergence of social media simplified the process, because they do not call for advanced internet knowledge or experience and are made up of a wide array of different formats and topics. This means that anyone can connect through social media (Sudha and Kavitha, 2016).

Social media became popular as a category of online plateform which enables people to create contents, share them, bookmark them and network at a fast rate (Jha and Bhardwaj, 2012). This has breached the gab that existed in communication where people had to rely solely on traditional methods such as letters and phone calls as a mode of getting in touch with friends and relatives. Today, communication is as easy as walking into a neighbor's residence to deliver a piece of information or vice versa through the use of social media. Social media is fast changing the public discourse in the society and is setting trends and 
agenda in topics that ranges from the environment and politics to technology and the entertainment industry (Asur and Huberman, 2010). The driving forces for adoption of social media are the progressively ubiquitous access, convenience, functionality, and flexibility of social technologies (Brown, 2010; Schroeder, Minocha and Schneider, 2010).

However, the use of social media is being rapidly rising during last few years. It is not only being used by the working people but also there is heavy increase in the use of social media by the students or education society (Raut and Patil, 2016). With such broad acceptance, there is no surprise that social media have affected the way people live and socialize. Social Networking Sites such as facebook, whatsapp, twitter, intagramme and snapchart are among the latest examples of communication technologies that have been widely-adopted by students and, subsequently, have the potential to become a valuable resource to support their educational communications and collaborations with faculty. Social media are mostly used by students to communicate and exchange ideas with lecturers specifically in western societies (Sudha and Kavitha, 2016). The development of technology, internet, and increase in social media usage has become a part of our daily lives. If social media is used in a positive way, it can help students and youth to get knowledge that can be used to improve their academic performances (Hasnain, Nasreen and Ijaz, 2015).

In Nigeria, the use of social media came to limelight in the wake of the Twenty-First Century. However, within a short period of its emergence on the Nigerian scene, social media underwent drastic transformation leading to it dominating in the field of interaction and interactivity among many Nigerians (Onwuka, 2013; Okpara, 2014). All over Nigeria, the students of tertiary institutions constitute a substantial portion of the users of social media. Majority of the students of Nigerian tertiary institutions make use at least one social media. The rate at which the students of Nigerian tertiary Institutions engage in social media and the amount of time they spend on them have raised a lot of concern among many thinkers with regard to their possible impacts on their academic performance (Okeke \& Oghenelaga, 2015; Oyedokun, 2014). Be that as it may, the exact nature of the impacts of the use of social media by the students of Nigerian tertiary institutions on their academic performance is still contentious and controversial. This study therefore intends to look at how exposure to social media affects students in Nigerian tertiary institutions, with a specific interest on the students of sociology and anthropology in university of Nigeria Nsukka.
ISSN 2455-6378

\section{Statement of the Problem}

The internet has become one of the most important sources of information, and of which the growing dimensions of the use of social media by students cannot be underestimated (Kolan and Dzandza, 2018). Thus it has been observed that students devote more attention and time to social media than they do for their studies and this results to low grades after examinations (Osharive, 2015). Also, the study conducted by Maya (2015) revealed that media use contributes to lower academic performance, low self perceptions and less interest in college oriented carriers. Academic excellence plays an important role in an individual's life; be it in the family, at social gatherings, at workplace, in an institution or even among peers. Much emphasis is placed on academic excellence because of the role it plays in an individual's life as far as a successful life and respect is concerned in every part of the world. Due to this, many people are concerned with the ways that they can improve their academic performances (Kyoshaba, 2009).

Thus, Onwuka (2013) maintained that the exact nature and character of the impacts of the uses of social media by the students of Nigerian Universities on their academic performance is highly debatable and controversial. While some analysts and scholars argued that the exposure of the students of Nigerian Universities to social media had made enormous positive impacts on their academic performance, other argue otherwise (Oyedekun, 2014). As can be seen from the above, the impacts of social media on the academic performance of students of Nigerian universities are still an issue area characterized by divergent views. It is plausible to note that as social media undergo more sophistication through the introduction of more advanced functionalities and applications by their owners, their usage by the students undergoes more intensification. This Scenario deepens the controversy over their impacts on the academic performance of the students. And despite the existence of awareness of the above issue and controversies, not much research work has not been carried out in this all- important area. It is therefore, within this problem area that the foundation of this research is anchored. Thus, the primary aim of this study is to assess the relationship between the use of social media and academic performances, and it impact on the students of sociology/anthropology in university of Nigeria Nsukka. 


\section{Research Questions}

1. What are the relationships between the use of social media and academic performances in Nigerian tertiary Institutions?

2. What impact do the social media have on the students of sociology/Anthropology in university of Nigeria Nsukka?

\section{Research Objectives}

1. To assess the relationships between the use of social media and academic performances in Nigerian tertiary Institutions?

2. To assess the impact of social media on the students of sociology/anthropology in university of Nigeria Nsukka.

\section{Research Hypothesis}

1. Students who use multiple social media are more likely to perform poorly in their academics than those who do not use social media.

2. Students who spend much time on the internet are more likely to have poor academic performance than those who do not spend much time.

3. Younger Students are more likely to use social media than older students.

\section{Significance of the Study}

This study can be a good academic source for researchers, especially in Nigeria, where there is more probably no such literature. This research will be as a trusted academic source and pave the way for scholars, lecturers and students to know the effects of social media, and the effects on the undergraduates' academic performances. It will raise the awareness of the people about either positive and negative impacts of social media on the academic performances of students in Nigerian society. It will also encourage students to use social media beneficially as effective communication tools as well as educational media to improve their knowledge and skills.

\section{Limitation of the Study}

The results of the current study are limited to the University students of Nigeria Nsukka, who are studying in the department of Sociology/Anthropology. It is just limited to assessing the relationship between the use of social media and academic performances, and it impact on the students of sociology/anthropology in university of Nigeria Nsukka.

\section{Literature Review}

There are many studies performed about the positive and negative effects of social media on the students' academic performances. For example, Heffner (2016) alleged that the use of social media can be a good outlet to deal with academic frustrations, especially if the students are in contact with other students that are having the same problem. Social media lets students to get connected with other students, which can be very useful because it will allow them to discuss class matters via social media.

Additionally, Helou (2014) tried to obtain students' perceptions of how their use of social networking sites influences their academic performances. The researchers performed a preliminary survey of a group of Malaysian university students. It was found that the majority of respondents agreed that the use of social media sites have a positive impact on their academic performances. Menseh and Nizam (2016) described that social media have a meaningful effect on the students' academic performances. They also pointed out about the abnormal use of social media platforms by students. The study suggested it is useful that universities and colleges in Malaysia educate their students to use these platforms positively for educational purposes which will ultimately result in a positive impact on their academic performance.

Jaipuria, and Sinha (2016) asserted that students are more probably affected by social media. To some extent, it absolutely affects the lives of college students with respect to grades. They added that social media is attractive as it gives college students another world to make friends, also provides a good way to release pressure. It was also noted that an approach is required to balance the relationship between social media and academic study. Consequently, college students should think more about the balancing of social media and academics. Additionally, the findings of a study conducted by Eke, Omekwu and Odoh (2014) among undergraduates in Nigeria showed that there are some benefits that comes from using social media, which encourages virtual meeting with co-research scholar; self-esteem and wellbeing; research and learning; strengthening interpersonal relationship; read and write web skills etc. It was also noted that students use social media to communicate with friends, viewing movies, for discussing national issues like politics, economy and religious matters, and for academic purposes. Mingle and Adams (2015) stated that some students experienced improvement in their reading skills as a result of participation and usage of social media. Also, respondents shared ideas, discussed and shared examination questions among themselves on social 
media. All the same, Mingle and Adams (2015) asserted that majority of respondents' experienced negative effects i.e. poor grammar and spelling, late submission of assignment, less study time and poor academic performance because of too much use of social media networks. Moreover, addiction towards the use of social media among students was high. Eke, Omekwu and Odoh (2014) described some dangers associated with social networking sites such as Ecrime, Internet addiction, laziness, standard crime like, fraud, murder, kidnapping; immoral act like, pornography, prostitution, cyber-bullying where identified.

In addition, the outcomes of a survey performed by Oblyer, McDaniel, Herman and Witty (2010) showed that faculty and students differ somewhat in their current and anticipated uses of social media such as facebook, whatsapp, instagram, snapchat and twitter. It was noted that there is a significant difference between the perceived role of this tool as social, rather than educational. Students look much more open to the idea of using Facebook instructionally than do faculty. Furthermore, most of the faculty members believed that social media have a negative effect on the students' academic performances compared with positive effects, due to lack of awareness among the students and faculty members about the appropriate usage of social media topics of educational interest. In the meantime, the positive effects of social media on their academic performances appeared to be significantly low (Sudha \& Kavitha, 2016).

Moreover, Heffner and Tara (2016) conducted a study among undergraduates at Rowan University of the USA. The study result shows that social media do not have a positive effect on the students' academic achievements because the student GPA decreased as much as they were engaged in social media. The study suggested the undergraduate students should manage and monitor their time spent using social media such as facebook, instagram, whatsapp, twitter and snapchart. In another study, Mushtaq (2015) discovered the use of social media as a factor that causes lack of habits of reading newspaper among students and it may cause them to lose much advantageous information contained in the newspaper.

Furthermore, Wang, Chen and Liang (2011) alleged that social networking is absolutely affecting students' effectiveness as well as their grades. Therefore, educators need to be worried about these problems and attempt to find better ways to solve these problems. Though, framed within an academic context, the concepts outlined here can be used to investigate the use of communication technology not only at school, but also at home, workplace, and many other settings, and for a diversity of different viewers like teenagers, young adults, the elderly, or families.

\section{Research Hypotheses}

The following hypotheses were formulated to guide the conduct of this research:

1. Students who use multiple social media are more likely to perform poorly in their academics than those who do not use social media.

2. Students who spend much time on the internet are more likely to have poor academic performance than those who do not spend much time.

3. Younger tudents are more likely to use social media than older students.

\section{Theoretical Orientation}

Social constructivism formed the theoretical orientation for this study. The theory was propounded by Berger and Luckman. It emphasizes that culture plays a great role in the cognitive development of an individual. Thus the theory focuses more on individuals' learning which takes place because of their interactions in a group (Raskin, 2002). However, one recent branch of work exploring social constructivism on learning focuses on the role of social technologies and social media in facilitating the generation of socially-constructed knowledge and understanding in online environments (Butt, 2001). Social constructivism can be applied in the analysis of the impacts of the exposure to social media on the academic performance of students as follows:

First, since one of the tenets of the theory is that the appropriate use of technological artifacts will facilitate the cognitive development of individuals, it therefore reason to say that the use of social networking site (a technological artifact)can facilitates the performance (a measure of cognitive development) of students.

Secondly, since social constructivism emphasizes that culture plays a great role in the cognitive development of individual, the activities, interactions, interactivities, texts, languages and other contents produced within a social media shall be taken as the aspects of the shared culture among the users of social media; then, the role of the above aspects of the social media culture in the academic performance of student-users of social media can be explained on the basis of the assumption that culture plays great role in the cognitive development of the individuals. 


\section{Research Methodology}

Research Design

Cross- sectional survey research design was used in carrying out this study.

Study Area

The study population is the University of Nigeria Nsukka located within Nsukka local government. The University of Nigeria, commonly referred to as UNN, is a federal university located in Nsukka, Enugu State, Nigeria. Founded in 1955 and formally opened on 7 October 1960. The University has two main campuses - Nsukka (University of Nigeria, Nsukka, UNN), Enugu (University of Nigeria Enugu campus, UNEC).

\section{Study Population}

This study centers on the undergraduate students of University of Nigeria while the target population focuses on the totality of undergraduate students of the Department of Sociology and Anthropology, University of Nigeria for the 2014/2015 academic session constitutes the population of this study. This population is made up of three hundred (300) students.

\section{Sample Size and Sampling Procedure}

A sample of one hundred and twenty (120) undergraduate students was drawn from the study population using simple random sampling technique by balloting.

\section{Instrument for Data Collection}

The questionnaire was used in this research. It was divided into two sections, namely: the preliminary section and the main section on the thematic issues. The preliminary section contains questions on the socio-demographic information of respondents while the main section contains questions on the thematic issues of the study.

\section{Method of Data Collection}

The data used in this research were collected through self-administered questionnaire.

\section{Method of Data Analysis}

The data generated in this research were analyzed using Statistical Package for Social Sciences (SPSS).Descriptive statistics such as frequencies and percentages were used to analyze the social-demographic information of respondents while chi-square statistics was used to test the hypotheses.

\section{Results}

Socio-demographic characteristics of the respondents

This section centers on the presentation and analysis of the socio-demographic characteristics of the respondents. Here, the age and sex distribution of the respondents, the distribution of the year of study of the respondents, the distribution of the sponsors of the respondents' education, occupational distribution of the sponsors of the respondents' education and income distribution of the parents (sponsors) of the respondents are tabulated and analyzed through the use of percentages.

TABLE 1: DISTRIBUTION OF RESPONDENTS BY AGE

\begin{tabular}{lcc}
\hline AGE & FREQUENCY & PERCENTAGE $(\%)$ \\
\hline 15-19 Years & 17 & 14.17 \\
20-24 Years & 66 & 55 \\
25-29 Years & 26 & 21.67 \\
30-34 Years & 5 & 4.17 \\
35-39 Years & 4 & 3.33 \\
40-44 Years & 2 & 1.67
\end{tabular}

SOURCE: Author's field survey, 2018.

TABLE 2: DESTRIBUTION OF RESPONDENTS BY SEX

\begin{tabular}{llc}
\hline SEX & FREQUENCY & PERCENTAGE $(\%)$ \\
\hline MALE & 63 & 52.5 \\
FEMALE & 57 & 47.5
\end{tabular}

SOURCE: Author's field survey, 2018. 
TABLE 3: DESTRIBUTION OF RESPONDENTS BY YEAR OF STUDY

\begin{tabular}{lcc}
\hline YEAR OF STUDY & FREQUENCY & PERCENTAGE $(\%)$ \\
\hline 100 LEVEL & 20 & 16.67 \\
200 LEVEL & 25 & 20.83 \\
300 LEVEL & 35 & 29.17 \\
400 LEVEL & 40 & 33.33
\end{tabular}

SOURCE: Author's field survey, 2018.

TABLE 4: DESTRIBUTION OF RESPONDENTS BY SPONSORS OCCUPATION

\begin{tabular}{lcc}
\hline SPONSORS OCCUPATION & FREQUENCY & PERCENTAGE $(\%)$ \\
\hline Civil Servant & 45 & 37.5 \\
Public Servant & 14 & 11.66 \\
Business & 61 & 50.83 \\
Farming & 0 & 0 \\
Others & 0 & 0
\end{tabular}

SOURCE: Author's field survey, 2018.

Information on the age distribution of the respondents shows that $14.17 \%$ of the respondents are between the age of 15 to 19 years, $55 \%$ of the respondents fall within the age range of 20 to 24 years, $21.67 \%$ of the respondents are between the age of 25 to 29 years, $4.17 \%$ of the respondents are between the age of 30 to 34 years, $3.33 \%$ of the respondents fall within the ages of 35 to 39 years, and $1.67 \%$ of the respondents are between $40-44$ years. As can be seen from the table, majority of the respondents $(55 \%)$ are between the ages of 20 to 24 years.

Information on the sex distribution of the respondents shows that $52.5 \%$ of the respondents are males while $47.5 \%$ are females. This implies that the majority of the respondents are males. Information on the Year of Study of the Respondents shows that $16.67 \%$ are 100 level Students, $20.83 \%$ are 200 level Students, $29.17 \%$ are 300 level Students, while 33.33 are 400 level Students. As can be seen from the table above, Majority of the respondents (62.5\%) are 300 and 400 level Students. Information on the distribution of the respondents according to the occupation of their sponsors indicate that $37.5 \%$ of the sponsors of the respondents are civil Servants, $11.66 \%$ of the sponsors of the respondents are public Servants while $50.83 \%$ of the sponsors of the respondents engage in business.

\section{Test of Hypotheses}

This section deals with the test of the four research hypotheses formulated to guide the conduct of this research. The Chi-square statistic is used to carry out the test.

\section{Hypothesis one}

Students who use multiple social media are more likely to perform poorly in their academics than those who do not use social media.

TABLE 5: DISTRIBUTION OF THE NUMBER OF SOCIAL MEDIA ACCOUNTS OPERATED BY THE RESPONDENTS AND THEIR LEVELS OF ACADEMIC PERFORMANCE.

\begin{tabular}{|c|c|c|c|c|}
\hline \multicolumn{3}{|c|}{ NUMBER OF SOCIAL MEDIA ACCOUNTS } & \multicolumn{2}{|c|}{$\begin{array}{l}\text { LEVELS OF ACADEMIC } \\
\text { PERFORMANCE }\end{array}$} \\
\hline & ABOVE AVERAGE & AVERAGE & BELOW AVERAGE & TOTAL \\
\hline 1 & $4(3.33)$ & $7(5.83)$ & $2(1.67)$ & $13(10.83)$ \\
\hline 2 & $11(9.17)$ & $19(15.83)$ & $1(0.83)$ & $31(25.83)$ \\
\hline 3 & $13(10.83)$ & $18(15)$ & $1(0.83)$ & $32(26.66)$ \\
\hline 4 & $7(5.83)$ & $16(13.33)$ & $2(1.67)$ & $25(20.83)$ \\
\hline 5and above & $5(4.17)$ & $13(10.83)$ & $1(0.83)$ & $19(15.83)$ \\
\hline TOTAL & $40(33.33)$ & $73(60.82)$ & $7(5.83)$ & $\mathbf{0 ( 1 0 0 )}$ \\
\hline
\end{tabular}

SOURCE: Field Survey, 2018 
The above contingency table shows that out of 40 students whose academic performance is above average, $3.33 \%$ operate 1 social media account, $9.17 \%$ operate 2 social media accounts, $10.33 \%$ operate 3 social media accounts, $5.83 \%$ operate 4 social media accounts while $4.17 \%$ operate 5 and above social media accounts. Also, out of 73 students whose academic performance is average, $5.83 \%$ operate 1 social media account, $15.83 \%$ operate 2 social media accounts, $15 \%$ operate 3 social media accounts, $13.33 \%$ operate 4 social media accounts while $10.83 \%$ operate 5 and above social media accounts. The table reveals that students academic performance are almost evenly distributed irrespective of the number of social media accounts. It shows, that the students' level of academic performance does not vary directly with the number of social media accounts they operate.

With the chi-sqaure value of 4.52 significant at 0.808 levels, there is no statistically Significant relationship between the number of social media accounts operated by students and their levels of academic Performance.

\section{Hypothesis Two}

Students who spend much time on the internet are more likely to have poor academic performance than those who do not spend much time.

TABLE 6: DISTRIBUTION OF RESPONDENTS ACCORDING TO THE AMOUNT OF TIME SPENT ON SOCIAL MEDIA BY RESPONDENTS AND THEIR LEVELS OF ACADEMIC PERFORMANCE.

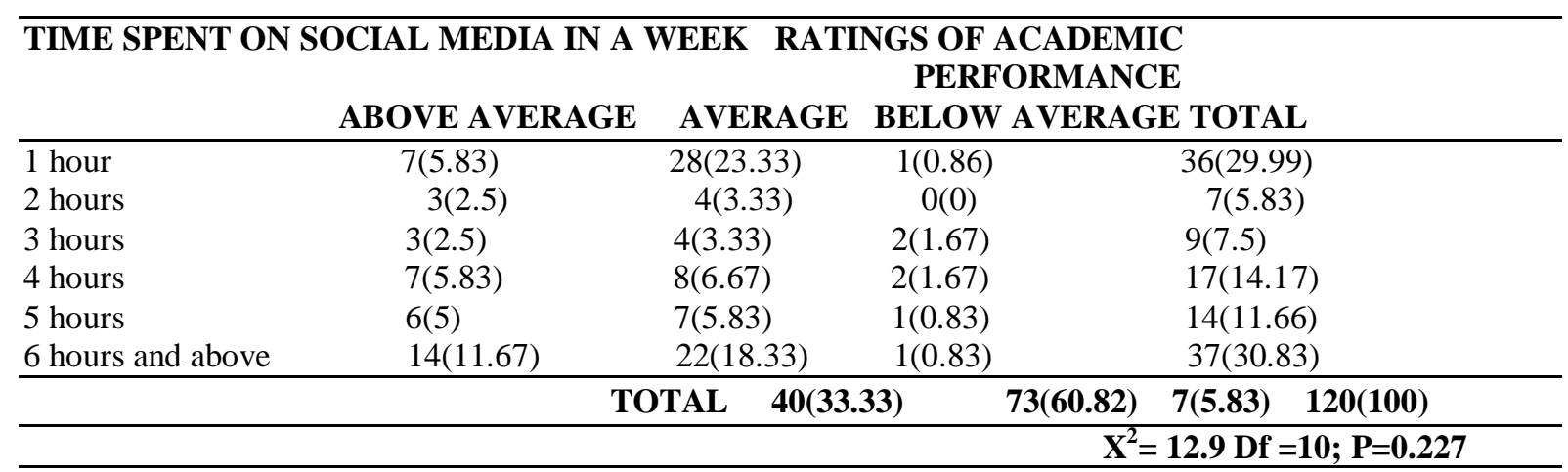

The above contingency table shows that out of 40 students or $33.33 \%$ of the respondents whose academic performance is above average; $11.67 \%$ spent 60 hours and above on social media in a week, $5 \%$ spend 5 hours on social media in a week, $5.83 \%$ spend 4 hours on social media in a week, $2.5 \%$ spent 3 hours on social media in a week, $2.5 \%$ spent 2 hours on social media in a week while $5.83 \%$ spent 1 hour on social media in a week. In the same vein, out of 73 students or $60.82 \%$ of the respondents whose academic Performance is average, $18.33 \%$ spent 6 hours and above on social media in a week, $5.83 \%$ spent 5 hours on social media in a week, $6.67 \%$ spent 4 hours on social media in a week,3.33\% spent 3 hours on social media in a week,3.33\% spent 2 hours on social media in a week while $23.33 \%$ spent 1 hour on social media in a week. The table reveals that the levels of academic performance do not depend on the amount of time they spent on social media .Students academic performance do not depend on the amount of time they spend on social media in a week.

The chi-square value of 12.9 was significant at 0.227 levels. It shows that there is no statistical significant relationship between the amount of time spent on social media by students and their levels of academic performance. The two variables under analysis are independent of each other.

\section{Hypothesis three}

Younger students are more likely to use the internet than older students. 
TABLE 7: DISTRIBUTION OF THE AGE OF THE STUDENTS AND THE AMONT OF TIME THEY SPENT ON SOCIAL MEDIA IN A WEEK.

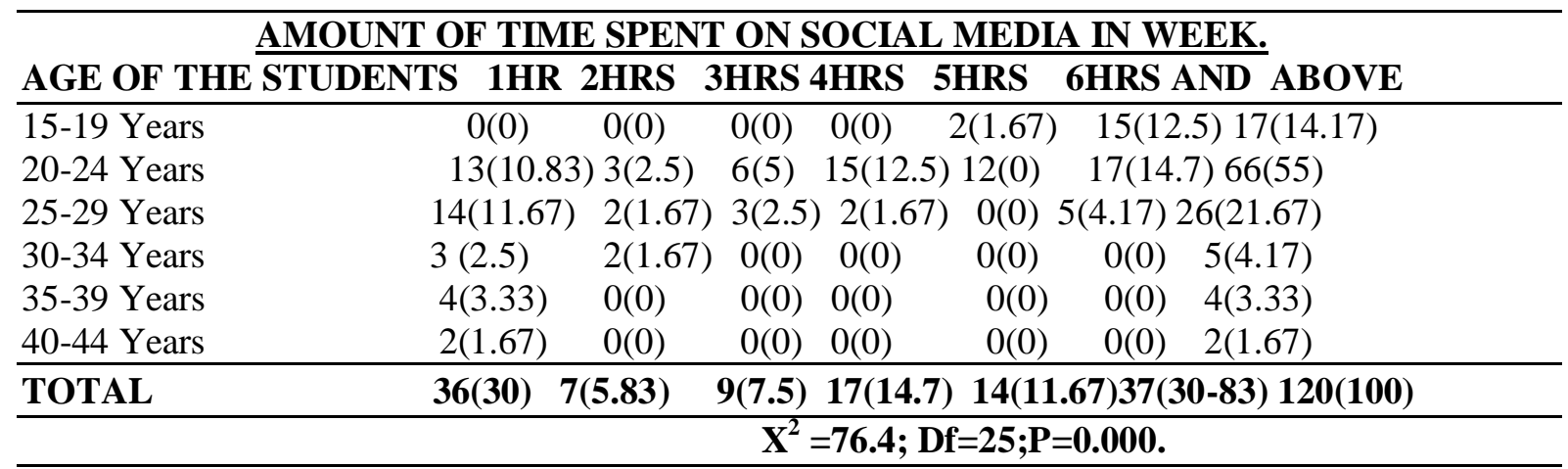

The above contingency table shows that out of 17 students or $14.17 \%$ of the respondents that are within the age range of 15 to 19 years, 15 spent minimum of 6 hours on social media in a week while 2 spent 5 hours on social media in a week. None of the students from the age of 30 years and above spent up to three hours on social media in a week. A good look at the table shows that the younger students spent more time on social media in a week than older students with the chi-square value of 76.4 significant at 0.000 levels. There is statistical significant relationship between the amount of time spent on social media in a week by students and their age.

\section{Discussion of Findings}

Based on the data analysis done in the preceding section, the following outcomes constitute the findings of this research:

1. Students who use multiple social media are not more likely to perform poorly in their academics than those who do not use social media. Students' academic performance is independent of their use of social media. Hence, there is no significant relationship between the number of social media accounts operated by students and their levels of academic performance. Also, there is no significant relationship between the number of visits to social media in a week by students and their levels of academic performance. More so, there is no significant relationship between the amount of time spent on social media in a week by students and their levels of academic performance.

2. Students who spend much time on the internet are not more likely to have poor performance in their academics than those who do not spend much time on the internet. There is no statistically significant relationship between the amount of time spent on the internet (social media) in a week by students and their levels of academic performance.
3. Younger students are more likely to use the internet than older students. There is significant relationship between the amount of time spent on social media in a week by students and their age range. The percentage analysis of table 25 reveals that younger students make more use of social media than older students.

\section{Recommendations}

Based on the findings presented in the
preceding followin0g recommendations are pertinent:

1. The university authority should create on-line educational and informational communities that will serve as platforms from which students can derive some academic values that will enhance their academic performance.

2. Students should place emphasis on the use of social media for academic purpose while de-emphasizing its use for non-academic purpose. Students should create educational communities through which they can be exchanging and crossfertilizing ideas in their various disciplines.

3. The university authority should integrate social media as part of its e-learning platform. The university authority should device efficacious strategies for optimal utilization of the platform for academic purpose after its integration into its elearning system. This will be supplemented by wellarticulated policies that will facilitate the proper and appropriate use of social media for academic purposes by students. It is believed that proper and pious utilization of the above recommendations will go a long way in enhancing the benefits of the use of social media by students.

4. Students must minimize the time they spend on social media to avoid being obsessed by these sites for unnecessary chatting. 
5. The university authority should also restrict access to certain social media sites that may be prone to distracting students' attention during school hours as a means of minimizing their use.

\section{References}

[1] Baran, S.J. (2000). Introduction to mass communication: Media Literacy and Culture. New York, United States of America: McGraw-Hill.

[2] Borgman, A. (1984). Technology and the character of contemporary life. Chicago, United States of America: University of Chicago Press.

[3] Castells, M. (2009). Communication power in New York. United States of America: Oxford University Press.

[4] Eric, H., Andrew, L. \& David, S. (2000). Technology and the good life. Chicago, United States of America: University of Chicago Press.

[5] Green, L. (2001).Technoculture: From alphabet to cybertex. Crows Nest, New South Wales, Australia: Allen and Unwin.

[6] Helou, A. M. (2014). The Influence of Social Networking Sites On Students'Academic Performance in Malaysia, International Journal of Electronic CommerceStudies, 5(2), 247254, doi: 10.7903/ijecs.1114.

[7] Higgs, E., Light, A., \& Strong, D.(2000). Technology and the good life. Chicago, The United States of America: University of Chicago press.

[8] Jan, K. \& Evan, S. (2006) Philosophy of technology: 5 Questions. New York, United States of America: Automatic Press.

[9] Junco, R., \& Loken, E. (2011). The Effect Of Twitter On College Students Engagement And Grades. Journal Of Computer Assisted Learning, 27(1), P.119.

[10] McLuhan, M. (1962). The Guttenberg Galaxy: The Maleing of Typographic Man. Toronto, Canada: University of Toronto Press.

[11] Mozee, S. (2015). The Impact of Social Media Use on Academic Performance at the one Urban University: A pilot study. "Retrieved from http: ILLISUMURC.ORG/Ojs/index.php\%3fjour nal

[12] Nayzabekov,S.(2015). "Negative Impact of social Networking Sites on Academic Performance of Students. Retrieved from http:///www.academia.edu/1810511/Negativ e Impact of Social.

[13] Okeke, C.E and Oghenelega,L.U. (2015). "The Impacts of Social Media on the Academic Performance of the University Students in Nigeria." Retrieved from
ISSN 2455-6378

http://www.15projects.com/projects/Impact s-of -Social media.

[14] Okpara,I.A.(2014). Perspectives in Contemporary Mass Communication. Ibadan, Nigeria: University Press Limited.

[15] Onwuka,S.U.(2013). A Modern Introduction to Mass Communication. Owerri, Nigeria: Wisdom Publishers Limited.

[16] Oyedokun, S.(2014). "Effects of Social Media (Facebook) on Nigerian Undergraduates. Retrieved December 17,2014 from http: //www.studymode.com

[17] Victor M. \& Kenneth,N.C (2013). Big Data: A Revolution that will transform How we Live, Work and Think. Houghton Mifflin Harcourt, United States of America: Eamon Dolan.

[18]Eke, Omekwu, at al (2014). "The Use of Social Networking Sites among the Undergraduate Students of University of Nigeria, Nsukka" Library Philosophy and Practice (e-journal).1195.

[19] Heffner, Tara. (2016). "The Effects of Social Media Use in Undergraduate Students" Theses and

i. Dissertations.

1440. http://rdw.rowan.edu/etd/1440.

[20] Hasnain, H. at al (2015). Impact of Social Media Usage on Academic Performance of University Students. 2nd International Research Management \& Innovation Conference (irmic 2015) langkawi, 26 - 27 august 2015.

[21]Helou, A. M. (2014). The Influence of Social Networking Sites On Students Academic Performance in Malaysia, International Journal of Electronic Commerce Studies, 5(2),247-254, doi: 10.7903/ijecs.1114.

[22] Jha, J. at al (2016). International Journal of Computer Applications (0975 - 8887) International Conference on Advances in Information Technology and Management ICAIM - 2016.

[23] Raut, V. at al (2016). Use of Social Media in Education: Positive and Negative impact on the students. International Journal on Recent and Innovation Trends in Computing and Communication ISSN: 23218169 Volume; 4 Issue: 1

[24] Roblyer, M. at al (2010). Findings On Facebook In Higher Education: A Comparison Of College Faculty And Student Uses And Perceptions Of Social Networking Sites. Elsevier. Internet and Higher Education 13 (2010) 134-140.

[25] Mingle, J. \& Adams, M. (2015). "Social Media Network Participation and Academic Performance in Senior High Schools in 
Ghana" Library Philosophy and Practice (ejournal).

1286 http://digitalcommons.unl.edu/libphilprac/1 286.

[26] Mushtaq, A, J. (2015). Habits And Motives Of Reading Among The Students In Alberoni University of Afghanistan. University Malaysia Pahang (UMP) \{Dissertation\}.

[27] Sudha, S \& Kavitha Es. (2016). "The Effect Of Social Networking On Students' Academic

[28] Performance: The Perspective Of Faculty Members Of Periyar University, Salem". library philosophy and practice (ejournal). 1455.
ISSN 2455-6378

[29] Jha, V. \& Bhardwaj, R. (2012). The New Marketing Renaissance: Paradigm Shift In Social

[30]Networks. International Journal Of Engineering And Management Sciences, 3(3) pp 384-

[31]387. Retrieved from www.scienceandnature.org.

[32] Mingle, J., \& Musah, A. (2015). Social Media Network Participation And AcademicPerformance In Senior High Schools In Ghana. Library philosophy and practice (ejournal).Paper 1286. Retrieved from

http://digitalcommons.unl.edu/libphilprac/1 286. 